\title{
Nutrigenomics: Understanding the Role of Nutrients and Gene Interactions in Periodontal Disease
}

Aparna Suraj Nellipunath ${ }^{1}$, Suchetha Aghanashini², Apoorva Sokke Mallikarjunappa ${ }^{3}$, Darshan Basavarajappa Mundinamane ${ }^{4}$, Sapna Nadiger ${ }^{5}$, Divya Bhat ${ }^{6}$

\begin{abstract}
Periodontal disease is a progressive inflammatory process, involving periodic destruction of periodontal attachment apparatus and loss of structures of the apparatus, essentially gingiva, periodontal ligament, cementum, and alveolar bone, ultimately resulting in loss of tooth in most susceptible patients. ${ }^{1}$ Advanced knowledge on the pathogenesis of periodontal destruction and the role of nutrients on it, has increased the interest to determine the relationship between periodontal disease and nutrition. ${ }^{2}$ It is also essential to know that periodontal disease risk is determined by genotype and dietary interactions. ${ }^{3}$ Nutrients that play an important role in inflammatory and immune responses can in turn regulate and modulate periodontal health. ${ }^{4}$ Nutrigenomics is a branch of nutritional genomics, which uses genomic tools in nutritional research to focus on the identification and understanding of the molecular-level interaction between nutrients and genomes. ${ }^{3}$ It provides information on the influence of nutrition on the metabolic pathways and homeostatic control and also allows us to know the disturbances arising in this regulation, at an early stage. ${ }^{5}$ This literature review provides a detailed description of the role of nutrition in periodontal disease and recommends the daily nutritional intake necessary for the prevention of periodontal disease. ${ }^{3}$
\end{abstract}

Keywords: Nutrigenomics, Nutrition, Periodontal disease.

Journal of Contemporary Dentistry (2019): 10.5005/jp-journals-10031-1274

\section{INTRODUCTION}

Periodontitis, a microbial inflammatory disease of the supporting structures of the teeth, results in continuous destruction of the supporting structures. ${ }^{6}$ Currently, $>85 \%$ prevalence rate of periodontal disease has been reported among the general population in India, and periodontal disease is considered as the second most-commonest disease around the world, after dental caries. $^{3,7}$

Various biological, environmental, and behavioral factors act as "risk factors", which increases the likelihood of developing a disease in an individual, such as, inflammation, during which there is depletion of antioxidant vitamins and trace elements. These depleted molecules later counteract with the reactive oxygen species (ROS) leading to periodontal changes. ${ }^{4,8}$ Nutrients constitute the dietary signals. ${ }^{5}$ Crucial interplay between the biological system (bacteria), environmental, genetic, and nutritional factors increases the susceptibility to periodontal disease. ${ }^{3,9}$

An emerging branch in the field of science and technology, "Nutrigenomics" plays a potential role in bringing about the changes in the future guidelines and recommendations of the diet. ${ }^{10}$ It concentrates on the interactions between the human genome and nutrients (Fig. 1), using modern tools, such as, epigenomics, proteomics, transcriptomics, and metabolomics (Flowchart 1).

The first nutrigenomics company was launched, in 1997. Nancy Fogg-Johnson and Alex Merolli changed the name nutritional genomics to genomics in 1999 and the term "nutrigenomics" was first described by Pelegrin in the year 2001.,11

\section{Scope of Periodontics}

There is an expanding scope of periodontics, which extends into various other specialties.

\footnotetext{
${ }^{1-6}$ Department of Periodontics, DA Pandu Memorial RV Dental College, Bengaluru, Karnataka, India
}

Corresponding Author: Aparna Suraj Nellipunath, Department of Periodontics, DA Pandu Memorial RV Dental College, Bengaluru, Karnataka, India, Phone:+91 9886041659, e-mail: akku23nellipunath@ gmail.com

How to cite this article: Nellipunath AS, Aghanashini S, Mallikarjunappa AS, et al. Nutrigenomics: Understanding the Role of Nutrients and Gene Interactions in Periodontal Disease. J Contemp Dent 2019;9(3): 135-140.

\section{Source of support: Nil}

Conflict of interest: None

\section{Nutrigenomics}

Is a newly emerging scientific field that is believed to have a serious role in the development of periodontal diseases. ${ }^{12}$

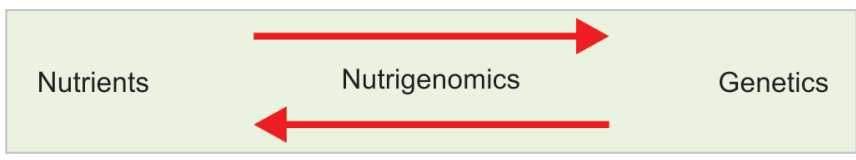

Fig. 1: Illustration of the nutrient-gene interaction

Flowchart 1: Tools of nutrigenomics

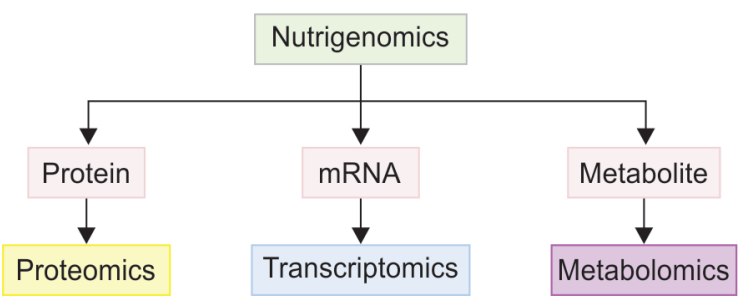

(0) The Author(s). 2019 Open Access This article is distributed under the terms of the Creative Commons Attribution 4.0 International License (https:// creativecommons.org/licenses/by-nc/4.0/), which permits unrestricted use, distribution, and non-commercial reproduction in any medium, provided you give appropriate credit to the original author(s) and the source, provide a link to the Creative Commons license, and indicate if changes were made. The Creative Commons Public Domain Dedication waiver (http://creativecommons.org/publicdomain/zero/1.0/) applies to the data made available in this article, unless otherwise stated. 


\section{Epigenetics}

Changes in the chromatin structure, results in a somatically heritable state of gene expression, without altering the DNA sequence, referred to as "epigenetics". It includes DNA methylation and histone modifications. ${ }^{13}$

\section{Proteomics, Transcriptomics, and Metabolomics}

The study of the proteome, and addressing its biological characteristics constitutes "Proteomics". The complete set of RNA that can be produced from a genome is called a transcriptome. The study of transcriptome, at the level of the mRNA, constitutes "Transcriptomics". The scientific study of chemical processes, involving metabolites is called "Metabolomics"."

\section{Biomarkers}

Various biomarkers have been identified for periodontal diseases, such as, genetic, proteomic, microbial, and others. ${ }^{12}$

\section{Objectives and Applications of Nutrigenomics}

- To identify the genes, present in disease and health capable of modifying the diet.

- To identify the specific genes/proteins, which can be modified by specific nutrients, that are beneficial or harmful to the body. ${ }^{14}$

- To identify the transcription factors that function as nutrient sensors.

- To develop specific biomarkers, using the nutritional systems biology, that is influenced by nutrition. ${ }^{11}$

- To achieve a better understanding of the safer upper and lower limits for essential macronutrients and micronutrients. ${ }^{15}$

\section{Effects of Nutrition on the Epigenetic Mechanisms \\ DNA Methylation}

Two metabolites of one-carbon metabolism are S-adenosyl methionine (AdoMet), and S-adenosyl homocysteine (AdoHcy). Thus, any nutrient that can affect AdoMet/AdoHcy levels in tissue can alter the DNA methylation. DNA hypermethylation status is reduced by genistein present in soybean, tea polyphenols, or isothiocyanates derived from plant foods, thereby inhibiting cancer.

\section{Histone Modifications}

Niacin is involved in histone adenosine diphosphate (ADP) ribosylation.

\section{Histone Acetylation}

Vitamin B3 and vitamin B5 are involved in histone acetylation. Enzymes of histone acetylation are histone deacetylase (HDAC) and histone acetyltransferases (HAT). Resveratrol (a bioactive component in grape skins) inhibits HDAC. Histone acetyltransferase is inhibited by curcumin.

\section{Histone Methylation}

Histone methylation is affected by vitamin B9, B12, choline, methionine, and betaine.

\section{Histone Biotinylation}

Deficiency of vitamin B7 (biotin) has a significant impact on chromatin structure, gene silencing, and DNA repair. ${ }^{13}$

\section{Discussion}

\section{Nutrient-Gene Interactions}

Nutrients can be classified into macronutrients (carbohydrates, fats, proteins, and water) and micronutrients (vitamins, minerals, and trace elements). Nutrition affects the transcription of genes $^{16}$ (Table 1). Along with genetics and diet, even the other environmental factors, such as, smoking, physical activity, etc., are also to be considered to optimize health. ${ }^{17}$

\section{Nutrigenomics: Effects on Periodontal HeALth \\ Role of Carbohydrates}

Artificial sweetener, xylitol, has an antibacterial effect against periodontal pathogens, Porphyromonas gingivalis and Aggregatibacter actinomycetemcomitans. Reduced intake of sugar, along with scaling and root planing (SRP), and the use of xylitolcontaining gums effectively improves the periodontal health of the general population.

\section{Role of Vitamins}

- Various researches indicate that there is an improvement in periodontal health upon vitamin A supplementation.

- While vitamin B supplementations may accelerate the postsurgical healing, the supplementation with vitamin $C$ may improve the periodontal therapy outcomes.

- Local application of vitamin D accelerates postsurgical healing/ osseointegration.

- Oxidative stress reduction action of dietary vitamins $E$ and $C$ have been studied in periodontium and patients undergoing nonsurgical periodontal therapy has shown to increase the total antioxidant capacity (TAOC) in supplementation with vitamin C.

Table 1: Most common transcription factors mediating the nutrient-gene interactions

\begin{tabular}{ll}
\hline Nutrient & Transcription factor \\
\hline Carbohydrates & $\begin{array}{l}\text { ChREBP (carbohydrate responsive element- } \\
\text { binding protein), SREBP (sterol responsive } \\
\text { element-binding protein), upstream stimulatory } \\
\text { factor }\end{array}$ \\
Proteins & EBPs (enhancer-binding protein) \\
Fats & PPARs (peroxisome proliferator-activated \\
& $\begin{array}{l}\text { receptor), LXR (liver X receptor), HNF } \\
\text { (hepatocyte nuclear factor) }\end{array}$ \\
Vitamins & RAR (retinoic acid receptor), RXR (retinoid X \\
Vitamin A & receptor) \\
Vitamin D & DR (vitamin D receptor) \\
Vitamin E & PXR (pregnane X receptor) \\
Minerals & Calcineurin/NF-ATs (nuclear factor of activated \\
Calcium & T cells) \\
Iron & IRP1, IRP2 (iron regulatory protein) \\
Zinc & MTF1 (metal responsive transcription factors) \\
Others & ER (estrogen receptor), NFKB (nuclear factor Kb), \\
Flavonoids & AP1 (activating protein 1) \\
Xenobiotics & PXR \\
\hline &
\end{tabular}




\section{Role of Minerals}

- Local application of calcium enhances osseointegration and outcomes of nonsurgical periodontal therapy have shown to improve with calcium supplementation.

- Magnesium supplementation also improves the nonsurgical periodontal therapy outcomes.

- Iron and zinc have an antioxidant effect on the periodontium. Zinc also reduces the severity of diabetes-induced periodontitis.

- Another important mineral that protects the teeth is fluoride. Supplementation with fluoride and its topical application prevents dental caries. ${ }^{18}$

Common Dietary Sources and Recommended Dietary Allowances (RDA*) of Nutrients (Table 2). ${ }^{19-23}$

\section{Effects of Nutrigenetic Interactions in Periodontal Disease}

\section{Macronutrients}

\section{Proteins}

Connective tissue degeneration of the gingiva and periodontal ligament, osteoporosis of alveolar bone, impaired cemental deposition, and delayed wound healing are the associated manifestations of protein deficiency. ${ }^{24}$

\section{Lipids}

Through biomarker analysis, a positive modulating effect of $n-3$ poly unsaturated fatty acids (PUFAs) has been suggested on gingival inflammation in animals. ${ }^{25}$ Kesavalu et al. ${ }^{26}$ hypothesized that omega ( $\omega)-3 / n-3$ fatty acids (FA) dietary supplementation, modulates the inflammatory reactions, leading to periodontal disease in infected rats. Female Sprague-Dawley rats were used in the study. Rats were fed with fish oil containing n-3 fatty acids or corn oil with n-6 FA diets for 22 weeks and infected with P. gingivalis. Diet-induced changes were documented in the rats on $\omega-3$ FA diet in the form of elevated serum eicosapentaenoic acid (EPA) and docosahexaenoic acid (DHA) levels. Porphyromonas gingivalis strains, mixed with equal amounts of $2 \%$ carboxymethylcellulose, were used orally to infect rats within 15 minutes of removal from the anaerobic environment. Polymerase chain reaction (PCR) was carried out, which showed a less alveolar bone resorption in $P$. gingivalis induced model of periodontitis. ${ }^{26}$

El-Sharkawy et al. evaluated the effects of dietary supplementation, in their study, which aimed to test an innovative strategy for periodontal treatment in a parallel-design, doublemasked clinical experiment on 80 healthy subjects (40 per group) with advanced chronic periodontitis. Plaque and gingival indices, bleeding on probing, probing depths, and attachment levels were recorded. ${ }^{27}$ While the control group received SRP and placebo, the test group was treated with SRP followed by dietary

Table 2: Common dietary sources and recommended dietary allowances (RDA) of nutrients

\begin{tabular}{|c|c|c|}
\hline Nutrient & Dietary sources & $R D A^{*} /$ day \\
\hline Vitamin A & $\begin{array}{l}\text { Oily fish, liver, eggs, and carotenoids containing dark green and yellow fruits and } \\
\text { non-citrus vegetables }\end{array}$ & Men and women: $100 \mu \mathrm{g}$ \\
\hline \multirow[t]{3}{*}{ Niacin } & Dairy products, eggs, meat, yeast extracts, and pulses & Men: 16 mg \\
\hline & & Women: 14 mg \\
\hline & & Pregnant women: $18 \mathrm{mg}$ \\
\hline \multirow[t]{2}{*}{ Pantothenic acid } & Chicken, beef, oats, liver, egg yolk, broccoli, etc. & Men and women: 5 mg \\
\hline & & Pregnant women: $6 \mathrm{mg}$ \\
\hline \multirow[t]{2}{*}{ Biotin } & Liver, smaller amounts in fruits and meats & Men and women: $30 \mu \mathrm{g}$ \\
\hline & & Pregnant women: $30 \mu \mathrm{g}$ \\
\hline Folate & $\begin{array}{l}\text { Dark leafy vegetables, enriched cereals grains, enriched and whole-grain bread } \\
\text { and bread products, etc. }\end{array}$ & Men and women: $400 \mu \mathrm{g}$ \\
\hline \multirow[t]{2}{*}{ Vitamin B12 } & Dairy products, meat, fish, eggs, fortified breakfast cereals & Men and women: $1.8 \mu \mathrm{g}$ \\
\hline & & Pregnant women: $2.6 \mu \mathrm{g}$ \\
\hline \multirow[t]{3}{*}{ Vitamin C } & Citrus fruits, bell peppers, parsley, berries, green vegetables, and potatoes & Men: $90 \mathrm{mg}$ \\
\hline & & Women: $75 \mathrm{mg}$ \\
\hline & & Pregnant women: $80-85 \mathrm{mg}$ \\
\hline Vitamin D & Sunlight, oily fish, eggs, fortified margarine & Men and women: $5 \mu \mathrm{g}$ \\
\hline Vitamin $\mathrm{E}$ & Sunflower seeds, vegetable oil, eggs & Men and women: $10 \mathrm{mg}$ \\
\hline \multirow[t]{2}{*}{ Iron } & Meat, fish, dark green vegetables, pulses, and fortified breakfast cereals & Men: $8 \mathrm{mg}$ \\
\hline & & Pregnant women: $18 \mathrm{mg}$ \\
\hline \multirow[t]{2}{*}{ Zinc } & Meat, poultry, dairy products, fish, shellfish, and pulses & Men and women: 8-11 mg \\
\hline & & Pregnant women: $12 \mathrm{mg}$ \\
\hline Selenium & Animal products & Men and women: 55 $\mu \mathrm{g}$ \\
\hline Calcium & Milk, cheese, yogurt, Chinese cabbage, broccoli & Men and women: 1,300 mg \\
\hline \multirow[t]{2}{*}{ Fluoride } & Fluoridated water, marine fish, teas, etc. & Men: 4 mg \\
\hline & & Women: $3 \mathrm{mg}$ \\
\hline \multirow[t]{3}{*}{ Magnesium } & Green leafy vegetables, unpolished grains, nuts, starches & Men: 240 mg \\
\hline & & Women: $240 \mathrm{mg}$ \\
\hline & & Pregnant women: $400 \mathrm{mg}$ \\
\hline
\end{tabular}


Flowchart 2: Key etiological factors in the development of periodontal disease

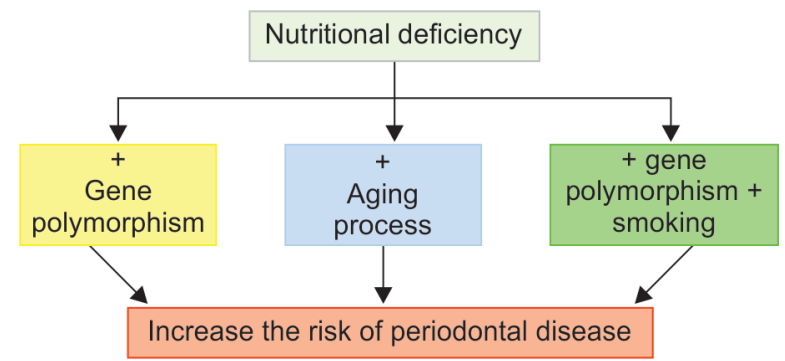

supplementation of omega-3 PUFAs and $81 \mathrm{mg}$ aspirin daily. A significant pocket depth reduction and attachment gain were showed after 3 and 6 months in the test group compared with the control group. Hence, adequate daily intake of fish oils are necessary for the prevention and treatment of periodontitis. ${ }^{25}$

\section{Micronutrients}

Dietary deficiency or lifestyle factors, resulting in decreased serum/ plasma micronutrient levels, may play a key etiological factor in the development of periodontal disease (Flowchart 2). ${ }^{1}$

\section{Role of Vitamins and Minerals Vitamin A}

Deficiency of this vitamin will lead to mucosal keratinization and leukoplakia.

\section{Vitamin B Complex}

A deficiency of vitamin B12 causes reversible dysplastic changes to the oral mucosa and recurrent ulcers. Vitamin B3 deficiency leads to mucosal atrophy and folate deficiency leads to candidosis. ${ }^{23}$

\section{Vitamin D and Calcium}

Vitamin D receptor (VDR) gene polymorphisms are associated with periodontitis. ${ }^{28}$ Decreased calcium absorption and increased osteoclastic activity of bone can be observed when the serum levels of $25(\mathrm{OH}) \mathrm{D}$ are low. Miley et al. ${ }^{29}$ conducted a study on the effects of vitamin $D$ and calcium supplementation on 51 chronic periodontitis subjects, of which, 23 subjects received vitamin $D$ ( $\geq 400 \mathrm{lU} /$ day) and calcium ( $\geq 1,000 \mathrm{mg} /$ day) supplementation, and 28 subjects did not receive such supplementation. Periodontal disease parameters, such as, gingival index, probing depth, attachment loss, bleeding upon probing, and furcation involvement, were recorded for the mandibular posterior teeth.

Exclusion criteria consisted of:

- Any periodontal surgery within the last year.

- Scaling and root planing, within the past 6 months.

- Diabetic history.

- History of diseases/conditions, or use of medications that might affect bone and mineral metabolism and/or periodontal health.

- Treatment with fluorides within the past 24 months.

- Treatment with estrogen within the last 6 months.

- Treatment with bisphosphonates in the past 12 months.

- Antibiotic therapy.

A trend toward better periodontal health was observed in subjects who received periodontal maintenance therapy with adjunctive vitamin $\mathrm{D}$ and calcium supplementation. ${ }^{25,29}$
Krall et al. obtained the information on tooth loss and oral health status, from 145 subjects aged 65 years/older, who completed a 3-year, randomized, placebo-controlled trial of the effect of vitamin $D$ and calcium supplementation on bone loss from the hip, as well as a 2-year follow-up study, during which supplements were discontinued. Subjects in the supplemented group received calcium citrate malate, $500 \mathrm{mg} /$ day, and cholecalciferol, $700 \mathrm{IU} /$ day. Subjects in the placebo group received the same number of pills, each containing microcrystalline. ${ }^{30}$ Results showed a significant reduction in osteoporosis and tooth loss, in subjects who were received calcium supplements. ${ }^{31}$

\section{Vitamin $E$}

Deficiency of vitamin E in humans is unlikely, as the vitamin is widely distributed in the diet. Therefore, a correlation between periodontal disease and vitamin E dietary deficiency cannot be established. ${ }^{32}$

\section{Vitamin C}

Nishida et al. conducted a study utilizing the survey conducted by NHANES III, on 12,419 adults (20-90+ years of age), with dental measurements and assessment of dietary vitamin C. Individuals with clinical attachment levels of $\geq 1.5 \mathrm{~mm}$, were arbitrarily defined as the periodontal disease group. A statistically significant dose-response relationship was observed between vitamin C and periodontal disease, with a low intake resulting in an increased risk of periodontal disease. ${ }^{33}$ Also, a higher risk of disease occurrence was found with low dietary vitamin C intake, among former and current smokers. Increased risk of periodontal destruction is found to be associated with IL-1, IL-1 $\beta$, and IL-RN genotypes polymorphisms. $^{31}$

Blignaut and Grobler $^{34}$ compared the periodontal condition of workers in citrus fruit-producing farms with those working in grainproducing farms. ${ }^{25}$ Workers of grain farms served as controls. CPITN index was used to record the periodontal status. ${ }^{34}$ Results showed a less frequency of deeper pockets in subjects who consumed citrus fruit.

The relationship between vitamin C deficiency and necrotizing ulcerative gingivitis has also been frequently described. ${ }^{25}$

Vogel et al. studied the effects of mega-doses of ascorbic acid/ vitamin- $C$ on neutrophil chemotaxis and experimental gingivitis, among 24 dental students (18 males and 6 females), divided into two groups. Students demonstrating clinical attachment loss/ moderate to severe gingivitis, or taking vitamin supplements/ having any systemic disease/taking any medication that affects the periodontium were excluded from the study. ${ }^{35}$ Results demonstrated that the daily dietary intake of vitamin $C$ was less in periodontitis individuals when compared with the control subjects. $^{36}$

\section{Zinc}

Using nutrigenomic techniques, Dang et al. investigated the efficacy of zinc supplementation, modified by SLC30A8 genotype, to improve beta-cell function in a rat cell-line model with diabetes. To investigate the potential impact of increased extracellular zinc on insulin secretion in the model, control/ZnT8 small interfering RNA knockdown beta cells were incubated, 24 hours before incubation with extracellular glucose. Based on the data collected, they hypothesized that zinc supplements may alter periodontal 
disease progression through changes in expression of the ZnT8 transporter gene.,

\section{Others}

Makimura et al. conducted a study to examine the inhibitory effects on collagenase activity by the catechin derivatives from Japanese green tea Camellia sinensis. Among the tea catechins tested, epicatechin gallate and epigallocatechin gallate showed the most potent inhibitory effect on collagenase activity, when an optimal concentration of tea catechins was added to a reaction mixture containing collagenase and collagen. ${ }^{37}$ Decrease in the clinical parameters, such as, mean pocket depth, clinical attachment loss, and bleeding on probing, was associated with every one cup/day increment in green tea intake.

The possible role of flavonoids in relation to the periodontal disease was supported by many animal studies, that investigated the effects of a cocoa-enriched diet on gingival oxidative stress in a rat-periodontitis model. ${ }^{25}$ Tomofuji et al. conducted a 4-week study on rats, which were divided into three groups ( $n=8 /$ group): A control group (fed with regular diet) and two periodontitis groups (fed with regular/cocoa-enriched diet). Periodontitis was induced in these models, by ligature placement around the mandibular first molars. Consuming a cocoa-enriched diet showed a diminished periodontitis-induced oxidative stress and a suppression in the progression of periodontitis. ${ }^{38}$

\section{Conclusion}

Nutrigenomics is currently showing tremendous success, since the development of personalized nutrition interventions is likely to induce large, appropriate, and consistent modifications in eating and lifestyle behaviors, supporting new preventive and therapeutic strategies. $^{39}$

The 2011 European Workshop on Periodontology recommends that the dental team, as a part of the periodontal prevention/ treatment regime, should consider to include fish oils, fruits and vegetables, fibers, and to reduce levels of refined sugars in the diet. ${ }^{40}$ Adequate daily intake of vitamin D and calcium are also recommended, for the prevention/treatment of periodontitis. ${ }^{41}$ It is expected shortly that, nutrigenomics will allow the identification and validation of new markers of cancer risk. ${ }^{42}$

Thus, a better understanding of the inter-relationships between the human genome function and dietary components are necessary to achieve stability throughout the life cycle, to result in optimal human health and disease prevention. ${ }^{43}$

\section{References}

1. Tomar N, Gupta C, Kaushik M, et al. Nutrigenomics: a perio-nutrition interrelationship. J Oral Res Rev 2017;9(1):32-36. DOI: 10.4103/22494987.201401.

2. Dang TS, Walker $M$, Ford $D$, et al. Nutrigenomics: the role of nutrients in gene expression. Periodontol 2000 2014;64(1):154-160. DOI: 10.1111/prd.12001.

3. Priyadharshini RS, Vijayalakshmi R, Ambalavanan N, et al. Nutrigenomics in periodontics-an overview. Int J Curr Res Rev 2016;8(1):31.

4. Shivanand S, Savita S, Rithesh K, et al. Nutrigenomics: a new paradigm for revealing periodontal inter-relationships. J Biomed Pharm Res 2016;5:7-15.

5. Müller M, Kersten S. Nutrigenomics: goals and strategies. Nat Rev Genet 2003;4(4):315-322. DOI: 10.1038/nrg1047.
6. Hinrichs JE, Kotsaki G, Naik DG. A Uppoor. Newman and Carranza's clinical periodontology. Classification of diseases and conditions affecting the periodontium. Newman and Carranza's Clinical Periodontology Newman MG, Takei HH, Klokkevold PR, et al., ed. 13th ed., Chandigarh: Elsevier Inc: University, Saunders; 2019. p. 301.

7. Spolsky VW, Naik DG, Uppoor A. . Newman and Carranza's clinical periodontology epidemiology of gingival and periodontal diseases. Newman and Carranza's Clinical Periodontology Newman MG, Takei $\mathrm{HH}$, Klokkevold PR, et al., ed. 13th ed., Chandigarh: Elsevier Inc: University, Saunders; 2019. p. 402.

8. Elangovan S, Novak KF, Novak MJ, et al. Newman and Carranza's clinical periodontology. Clinical risk assessment. Newman And Carranza's Clinical Periodontology Newman MG, Takei HH, Klokkevold PR, et al., ed. 13th ed., Chandigarh: Elsevier Inc: University, Saunders; 2019. p. 1515.

9. Mutch DM, Wahli W, Williamson G. Nutrigenomics and nutrigenetics: the emerging faces of nutrition. FASEB J 2005;19(12):1602-1616. DOI: 10.1096/fj.05-3911rev.

10. Ordovas JM, Corella D. Nutritional genomics. Annu Rev Genomics Hum Genet 2004;5(1):71-118. DOI: 10.1146/annurev. genom.5.061903.180008.

11. Balaji Ganesh S, Sugumar K. Nutrigenomics: a new direction in periodontics. IJADS 2020;6(1):146-149.

12. Jain $Y$, Valluri $R$, Srikanth $C$, et al. The expanding scope of periodontics-a review article. Int J Cur Res Rev 2019;11(24):1. DOI: 10.31782/IJCRR.2019.11241.

13. Choi SW, Friso S. Epigenetics: a new bridge between nutrition and health. Adv Nutr 2010;1(1):8-16. DOI: 10.3945/an.110.1004.

14. Kornman KS, Martha PM, Duff GW. Genetic variations and inflammation. Nutrition 2004;20(1):44. DOI: 10.1016/j.nut.2003.09.008.

15. Kumar N, Maheshwari KK. 20 Nutrigenomics: nurturing of genotype and role in human health. Phytochem Nutraceut Import 2014. 324.

16. Roberts MA, Mutch DM, German JB. Genomics: food and nutrition. Curr Opin Biotechnol 2001;12(5):516-522. DOI: 10.1016/S09581669(00)00256-1.

17. Corella D, Ordovas JM. Nutrigenomics in cardiovascular medicine. Circulat: Cardiovas Genet 2009;2(6):637-651.

18. Najeeb S, Zafar MS, Khurshid Z, et al. The role of nutrition in periodontal health: an update. Nutrients 2016;8(9):530. DOI: 10.3390/ nu8090530.

19. Chawla J, Kvarnberg D. Hydrosoluble vitamins. Handbook of clinical neurology, vol. 120. Elsevier; 2014. pp. 891-914.

20. Young VR, Newberne PM. Vitamins and cancer prevention: issues and dilemmas. Cancer 1981;47(S5):1226-1240. DOI: 10.1002/1097-0142(19810301)47:5+<1226::AID CNCR2820471329>3.0.CO;2-B

21. Rolfes SR, Pinna K, Whitney EN. Understanding Normal and Clinical Nutrition. Cengage learning; 2020. pp. 292-392.

22. Yates AA, Schlicker SA, Suitor CW. Dietary reference intakes: the new basis for recommendations for calcium and related nutrients, B vitamins, and choline. J Am Diet Assoc 1998;98(6):699-706. DOI: 10.1016/S0002-8223(98)00160-6.

23. Papas AS. Nutrition and Oral Medicine Touger-Decker R, Sirois DA, Mobley CC, ed. hardcover, \$135, Totowa, NJ: Humana Press; 2004. p. 379.

24. Klokkevold PR, Mealey BL, Ambalavanan N. Newman and Carranza's clinical periodontology. Influence of systemic conditions on the periodontium. Newman and Carranza's Clinical Periodontology Newman MG, Takei HH, Klokkevold PR, et al., ed. 13th ed., Chandigarh: Elsevier Inc: University, Saunders; 2019. p. 763.

25. Van der Velden U, Kuzmanova D, Chapple IL. Micronutritional approaches to periodontal therapy. J Clin Periodontol 2011;38:142158. DOI: 10.1111/j.1600-051X.2010.01663.x.

26. Kesavalu L, Vasudevan B, Raghu B, et al. Omega-3 fatty acid effect on alveolar bone loss in rats. J Dent Res 2006;85(7):648-652. DOI: $10.1177 / 154405910608500713$.

27. El-Sharkawy H, Aboelsaad N, Eliwa M, et al. Adjunctive treatment of chronic periodontitis with daily dietary supplementation 
with omega-3 fatty acids and low-dose aspirin. J Periodontol 2010;81(11):1635-1643. DOI: 10.1902/jop.2010.090628.

28. Sharma H, Arora R, Bhatnagar MA. Reconnoitering the relationship between "The sunshine Vitamin" and periodontal disease. J Oral Res Rev 2017;9(2):89. DOI: 10.4103/jorr.jorr_18_17.

29. Miley DD, Garcia MN, Hildebolt CF, et al. Cross-sectional study of vitamin $D$ and calcium supplementation effects on chronic periodontitis. J Periodontol 2009;80(9):1433-1439. DOI: 10.1902/ jop.2009.090077.

30. Krall EA, Wehler C, Garcia RI, et al. Calcium and vitamin D supplements reduce tooth loss in the elderly. Am J Med 2001;111(6):452-456. DOI: 10.1016/S0002-9343(01)00899-3.

31. Nunn ME. Understanding the etiology of periodontitis: an overview of periodontal risk factors. Periodontol 2000 2003;32(1):11-23. DOI: 10.1046/j.0906-6713.2002.03202.x.

32. Slade JE, Bartuska D, Rose LF, et al. Vitamin E and periodontal disease. J Periodontol 1976;47(6):352-354. DOI: 10.1902/jop.1976. 47.6.352.

33. Nishida M, Grossi SG, Dunford RG, et al. Dietary vitamin C and the risk for periodontal disease. J Periodontol 2000;71(8):1215-1223. DOI: 10.1902/jop.2000.71.8.1215.

34. Blignaut JB, Grobler SR. High fruit consumption and the periodontal status of farm workers. Clin Prev Dent 1992;14(2):25.
35. Vogel RI, Lamster IB, Wechsler SA, et al. The effects of megadoses of ascorbic acid on PMN chemotaxis and experimental gingivitis. J Periodontol 1986;57(8):472-479. DOI: 10.1902/jop.1986.57.8.472.

36. Van der Velden $\mathrm{U}$. Vitamin $\mathrm{C}$ and its role in periodontal diseasesthe past and the present: a narrative review. Oral Health Prev Dent 2020;18(2):115-124.

37. Makimura M, Hirasawa M, Kobayashi K, et al. Inhibitory effect of tea catechins on collagenase activity. J Periodontol 1993;64(7):630-636. DOI: 10.1902/jop.1993.64.7.630.

38. Tomofuji T, Ekuni D, Irie K, et al. Preventive effects of a cocoa-enriched diet on gingival oxidative stress in experimental periodontitis. J Periodontol 2009;80(11):1799-1808. DOI: 10.1902/jop.2009.090270.

39. Rescigno T, Micolucci L, Tecce MF, et al. Bioactive nutrients and nutrigenomics in age-related diseases. Molecules 2017;22(1):105. DOI: $10.3390 /$ molecules22010105.

40. Singh S, Kalra P. Nutrigenomics in periodontics-an overview. Int J Oral Health Dentis 2017;3(2):74-76.

41. Fogg-Johnson N, Kaput J. Nutrigenomics: an emerging scientific discipline. Food Technol (Chicago) 2003;57(4):60-67.

42. Daniel H. Genomics and proteomics: importance for the future of nutrition research. Br J Nutrit 2002;87(S2):S305-S311. DOI: 10.1079/ BJN/2002554.

43. Farhud DD, Yeganeh MZ, Yeganeh MZ. Nutrigenomics and nutrigenetics. Iran J Public Health 2010;39(4):1. 